\title{
Numerical simulation of two-dimensional in-plane crack propagation in FRP laminates
}

\author{
Aida Cameselle-Molares ${ }^{\mathrm{a}}$, Anastasios P. Vassilopoulos ${ }^{\mathrm{a}}$, Jordi Renart ${ }^{\mathrm{b}}$, Albert Turon ${ }^{\mathrm{b}}$, \\ Thomas Keller ${ }^{a^{*}}$ \\ ${ }^{a}$ Composite Construction Laboratory (CCLab), École Polytechnique Fédérale de Lausanne \\ (EPFL), Station 16, Bâtiment BP, CH-1015 Lausanne, Switzerland \\ ${ }^{\mathrm{b}}$ AMADE, Mechanical Engineering and Industrial Construction Department, Universitat de \\ Girona, Campus Montilivi s/n, Girona, Spain
}

\begin{abstract}
A numerical investigation was carried out in order to simulate experimental results previously obtained concerning two-dimensional (2D) in-plane crack propagation in laminated glass fiberreinforced polymer (GFRP) plates. The laminated plates were designed with an embedded circular pre-crack and subjected to quasi-static out-of-plane loads. In order to study the transition from standard fracture mechanics tests, where the crack propagates only in one dimension (1D), to 2D scenarios, additional double cantilever beam (DCB) experiments were carried out on the same material system. Three-dimensional finite element models were developed for the simulation of the experimental fracture responses and cohesive elements were used to take into account the fracture mechanisms acting on the fracture process zone. Compared to the 1D DCB specimens, a much higher value of the total strain energy release rate (SERR) was obtained for the 2D plates, which was correlated to their higher flexural stiffness and to the stress stiffening effect caused by the stretching of their deformed part. Furthermore, and based on the numerical results, it was proved that the area of the fully developed fiberbridging in the plates can be directly obtained from the experimental compliance vs crack area curves.
\end{abstract}

Keywords: 2D crack propagation; laminates; fracture; fiber-bridging; finite element analysis.

\section{Introduction}

Despite the good structural performance of fiber-reinforced composite materials (FRPs) [1], mechanisms such as delamination in laminated components may lead to a considerable

\footnotetext{
${ }^{*}$ Corresponding author. Tel: +41216933226; e-mail: thomas.keller@epfl.ch
} 
reduction in the load-bearing capacity of the structure. Significant efforts have been devoted to the investigation of the delamination fracture behavior of laminated composites [2-4]. Pure and mixed-mode fracture behaviors have been widely investigated, i.e. beam-like specimens such as the double cantilever beam (DCB) for Mode I, end-loaded split (ELS) for Mode II or mixedmode bending for mixed-Mode I/II, have all been extensively used and standardized [5-7]. However, some of the conditions required by these types of experiments, such as a constant crack width or single direction of propagation, may not correspond to the actual delamination damage growth that occurs in FRP structures. In many scenarios, delamination damage may develop all around the contour of a defect with an increasing length of the front of the propagating crack. Furthermore, accurate determination of the strain energy release rate (SERR) is a key factor for damage-tolerant structural design and therefore the development of new fracture experimental designs better able to represent realistic scenarios is needed. Some investigations studying the two-dimensional (2D) propagation of an embedded pre-crack in composite materials can be found in [8-13]. Various sources of delamination are considered: buckling-driven delamination in [8-11] or out-of-plane deformation of the laminate around a disbond due to differences in pressure in [12-13]. However, in all of them, the fracture properties were assumed to be those obtained from the previously mentioned standard beamlike specimens with one-dimensional (1D) crack propagation.

When a material undergoes deformation and damage, different toughening mechanisms may be activated, increasing the energy dissipation level. These damage mechanisms can be considered intrinsic or extrinsic, depending on whether they appear behind or in front of the crack tip respectively [14]. Intrinsic damage is related to the fracture resistance of a material and typically associated with plasticity in ductile materials such as metals or soft polymers, e.g., thermoplastics. On the other hand, extrinsic damage appears in front of the crack and is the main source of toughening in quasi-brittle materials such as thermoset FRPs. Fiber-bridging, matrix cracking and fiber pull-outs are some of the processes considered as extrinsic damage $[15,16]$, which occur in the fracture process zone (FPZ). Fiber-bridging is considered the most efficient of these to reduce the strain/stress level at the crack tip $[15,17]$ and thus increase the SERR value required to further extend the crack. This behavior is reflected in the resistance curves (R-curves) which typically present initially increasing SERR values for small crack lengths, and then reach a steady-state plateau for crack lengths corresponding to fully developed fiber-bridging $[17,18]$. When the length of the fiber-bridging is comparable to or greater than one of the dimensions of the specimen/component in which the crack is propagating (usually 
called large-scale bridging, LSB), the R-curve has been proved to be size and geometry dependent [19-21]. The prediction of the structural response by means of linear elastic fracture mechanics (LEFMs) only applies for small FPZs where the damage can be reduced to one point (the crack tip), i.e. no significant extrinsic mechanisms develop. If this condition does not apply, more complex methods are required [22-24]. Cohesive zone models (CZMs) [25-27] have been widely and successfully used for the simulation of fracture in many quasi-brittle materials [28] and have been proved particularly accurate in cases of materials developing a long FPZ with a high fiber-bridging contribution [29-30]. In the cohesive model the cohesive stresses (also named tractions) inside the FPZ tend to close the crack. The cohesive law describes the evolution of these tractions as a function of the crack-opening displacement. Based on this, the bridging fibers are considered as tractions along the bridging length, resulting in the so-called bridging law [24] that has usually been considered as a material property regardless of the size and geometry of the system [19,31-32]. This implies the assumption of the value of the SERR at the steady state as a material property [33]. Nevertheless, as previously mentioned, the Rcurves of materials presenting LSB are strongly dependent on the specimen's geometry and therefore any experimentally or numerically derived bridging law cannot be considered as a material property. Although some studies have described effects of thickness variation in the increasing part of the R-curves [29], recent investigations [15, 17, 33-34] have also reported a high influence of this parameter on the steady-state SERR value (plateau of the R-curve) of DCB specimens, proving a considerable influence of stiffness in the development of the fracture mechanisms and fiber-bridging in particular. Micromechanical models of DCB specimens with different thicknesses were developed in [15] showing that the extension of the fiber-bridging was dependent on the curvature of the arms. Thicker, therefore stiffer, and less curved arms presented longer bridging lengths and thus increased fiber-bridging.

The experimental fracture behavior of laminated FRP plates with an embedded circular precrack (i.e. 2D delamination) and subjected to quasi-static out-of-plane opening loads - similar to the loads applied in a DCB - was investigated in [35]. The results of these experiments showed that due to the boundary conditions inherent to an embedded pre-crack growing in a plate, stretching stresses appeared in the circumferential and radial directions resulting in a stiffening of the plate, in addition to the general increase in the flexural stiffness that occurs due to the transition from the (1D) beam to the (2D) plate configuration [35].

The objective of this work was the numerical investigation of the 2D in-plane crack propagation in two of the laminated plates presented in [35], in order to better understand the nature of the 
aforementioned additional stiffening effects and the associated mechanisms. The material system of the selected plates was glass/epoxy with a long continuous filament mat reinforcement whose nature led to the development of a considerable amount of fiber-bridging. For the sake of comparison and to understand the transition from standard 1D fracture experiments to 2D crack propagation scenarios, DCB specimens with different widths were further experimentally investigated. Three-dimensional finite element models were developed to simulate the experimental fracture responses of the plates and the DCBs using cohesive elements to take into account the fracture mechanisms acting on the FPZ. The influence of the parameters of the traction-separation laws on the load-displacement curves of the two investigated configurations was analyzed.

\section{Experimental methods}

\subsection{Previous experimental investigation of laminated plates}

The 2D delamination behavior of FRP laminated plates under quasi-static out-of-plane opening loading was experimentally investigated in [35]. The experimental program was conducted on twelve GFRP/epoxy plates comprising different glass reinforcements. The investigation presented here involves the two plates with six layers of long continuous glass filament mat reinforcement (CFM). A detail of the fiber reinforcement is given in Fig.1(a) and the properties of the glass fibers and epoxy resin are given in Table 1 (manufacturer data [36-37]). The plates were fabricated using a vacuum infusion process with an embedded circular pre-crack in the center and at the midplane. The layup and geometrical description are presented in Table 2 and the crack propagation pattern obtained for one of the plates is shown in Fig. 1(b). An example of the experimental set-up for the CFM.2 plate is presented in Fig. 2(a). Due to the high translucency of the laminates, the crack tip could be precisely identified through the occurring whitening of the delaminated areas. To monitor the position of the crack tip three different measuring systems were employed: a 3D Digital Image Correlation System (DIC), a digital camera and visual measurements (see Fig. $2(a, b)$ ). Eight rulers starting from the end of the pre-crack were drawn on the plates corresponding to eight directions of propagation, named after the cardinal directions (see "Crack measuring system" in Figure 2 (a)). The propagation along the east ("E") direction was measured by the DIC system $(0.2 \mathrm{~Hz}$ of acquisition frequency and accuracy of $\pm 0.005 \mathrm{~mm}$ ). The direction of propagation monitored with the digital camera (also acquisition frequency of $0.2 \mathrm{~Hz}$ ) was northwest ("NW"). Along the remaining directions, the crack front was recorded visually and in-situ during the experiments. From these experimental values, average curves (one per plate) of radial crack length were obtained and 
used to derive a continuous progression of the circular crack area. The load and opening displacement were obtained from the machine $(\mathrm{W}+\mathrm{B}$ electromechanic machine of $50-\mathrm{kN}$ capacity, $\pm 0.11 \%$ accuracy). Further details concerning the measuring methodologies can be found in [35].

A DCB specimen of 25-mm width and 220-mm length was radially cut from the CFM.1 plate, see Fig. 1(b), to perform a cantilever beam bending test at different clamping distances on the un-cracked region and derive the in-plane E-moduli of the plate. An experimental value of 8.64 GPa was obtained and used in the numerical model of the plates. This value differed by less than $10 \%$ from the analytically estimated value (see [35]) (see Table 3). The in-plane shear modulus was calculated for an isotropic material with a previously estimated in-plane Poisson ratio and the remaining out-of-plane properties were assumed to be the estimated values. These updated values were used for all the numerical simulations of the plates presented.

\subsection{Experimental investigation of Mode I DCB specimens}

Double cantilever beam (DCB) specimens were used to determine the Mode I SERR (see Fig. 3). The same material system (long continuous glass filament mat reinforcement/epoxy resin) and lay-up (six layers of $600 \mathrm{~g} / \mathrm{m}^{2}$ ) as those of the previously studied plates were used. A vacuum infusion process was employed for fabrication of the laminates and a Teflon film of $13-\mu \mathrm{m}$ thickness was placed at the midplane to introduce the pre-cracks. The infusion and curing protocols were identical to those of the plates (see [35] for further details). Once cured, the DCB specimens were cut from the laminates by means of a water jet machine. Specimens of four different widths, $b,(25,40,60$ and $100 \mathrm{~mm})$ were investigated to determine any possible influence of this parameter on the experimental SERR. Two fabrications were carried out and due to small differences in the vacuum level of the pump, small discrepancies in thickness, $h$, and consequently the E-modulus existed. Specimens of 25- and 40-mm width were cut from the first fabrication, with an average thickness value of $7.64 \pm 0.01-\mathrm{mm}$ while specimens of 60 and $100-\mathrm{mm}$ width were cut from the second fabrication, with a corresponding average thickness of $6.80 \pm 0.01-\mathrm{mm}$. As mentioned above, another DCB specimen of $25-\mathrm{mm}$ width (DCB-25-3) was cut directly in the radial direction from the CFM.1 plate.

To allow the transfer of the load from the loading frame to the specimens, two different types of loading blocks were used. For all the DCB specimens except DCB-25-3, adhesively-bonded “in-house fabricated" piano-hinged loading blocks (see Fig. 3(a)) were employed. For specimen 
DCB-25-3, patented [38] mechanically-fixed loading blocks were used (Fig. 3(b)). The geometrical and elastic properties of the DCB specimens are presented in Table 4.

The experiments were performed under displacement-control on a 100-kN MTS Landmark servo-hydraulic testing rig with a load cell of $25 \mathrm{kN}$ calibrated to $20 \%$ of its maximum capacity at a rate of $2.5 \mathrm{~mm} / \mathrm{min}$. All the experiments were conducted under laboratory conditions, $21 \pm 3^{\circ} \mathrm{C}$ and $40 \pm 10 \% \mathrm{RH}$.

The experimental set-up and instrumentation layout are shown in Fig. 4(a). The crack length was monitored with a digital camera (camera 1 in Fig. 4(a)) placed above the highly translucent specimens focusing on the grid ruler drawn over the upper surface (see Fig. 4 (b and c)). The grid size was set to $1 \mathrm{~mm}$ over the first centimeter after the crack tip and to $5 \mathrm{~mm}$ over the rest of the length. The acquisition frequency was set to $0.2 \mathrm{~Hz}$ and each picture was registered with the corresponding load and displacement values recorded by the machine (accuracy of $\pm 0.5 \%$ ). Additionally, in order to monitor the bridging length from the side of the specimens, a second digital camera (camera 2 in Fig. 4(a)), also synchronized with the machine, was used. The same acquisition frequency was set and the opening displacement between the arms was monitored by pairs of black dots (with an accuracy of $10^{-5} \mathrm{~m}$ ) marked at equal intervals of around $2 \mathrm{~mm}$ on the upper and lower lateral surfaces of the specimens (see Fig. 4 (d)).

\section{Numerical methods}

\subsection{Description of numerical model of laminated plates}

A finite element (FE) model was developed to simulate the delamination behavior of the CFM plates using the commercial finite element analysis (FEA) software ABAQUS 6.14.1. The dimensions of the model are presented in Fig. 5. The built-in continuum shell element of eight nodes and reduced integration (CS8R) from Abaqus/Standard was used to mesh the GFRP bulk material [39]. Two through-thickness elements were assigned to each of the halves (in relation to the midplane) of the plate, which, after a sensitivity analysis, proved to be sufficient to capture the bending behavior accurately. A single zero-thickness layer of three-dimensional cohesive elements of eight nodes (Abaqus COH3D8 [39]) was implemented at the midplane of the un-cracked region (Fig. 5). To assure a correct dissipation of energy during delamination, a minimum of fifteen elements in the cohesive zone length (CZL) (i.e. the length along the plane of the crack along which the cohesive forces were acting) was guaranteed throughout the analysis [40]. The greatest dimension of the elements of the model varied from $0.6 \mathrm{~mm}$ in the un-cracked region close to the pre-crack to $4 \mathrm{~mm}$ at the boundaries. The engineering constants 
used to define the bulk material are presented in Table 3. The nonlinear geometry (NLGEOM) option was used to account for large deformation effects.

Two symmetry planes (D1 and D2) coincident with the diagonals of the plates were considered and therefore corresponding symmetric boundary conditions were applied (see Fig. 5). The steel inserts and external loading blocks [35] were not explicitly modeled. Instead, the nodes of the inner faces of the loading areas (spanning from the center of the plates to the loading circumference, i.e. a radius of $35 \mathrm{~mm}$, "referenced areas" in Fig. 5 and [35]) were tied by means of a rigid body condition [39] to reference points (indicated in Fig. 5) where the boundary conditions were applied. An out-of-plane displacement condition (in-plane displacements constrained) was applied to the upper reference point and a pinned condition (all displacements constrained) to the bottom reference point. To capture the behavior of the complex loading system, whose rotations were partially impeded due to the upper and lower external steel plates, equivalent in-plane E-moduli and shear modulus, stiffer than the values used for the bulk material (see Table 3), were calibrated for these regions by an iterative procedure to fit the initial slope of the experimental curves. Resulting fitted values were $E_{1}=E_{2}=42 \mathrm{GPa}$ and $G_{12}=15.8 \mathrm{GPa}$. The model comprised 75146 nodes and 56664 elements. As in the experiments, the boundary edges of the plate were free.

To determine any possible contribution of shear fracture modes (Mode II and Mode III) in addition to the obvious opening fracture mode (Mode I), the shear displacements in the cohesive elements were also computed. Insignificant and close-to-zero values were always obtained assuring a pure opening mode propagation of the crack.

\subsection{Description of numerical model of DCB specimens}

For the numerical simulation of the DCB experiments, the FEA software ABAQUS 6.14.1 was also employed. The two GFRP beams were modeled with 3D built-in continuum shell elements (CS8R) as for the plate and a single zero-thickness layer of three-dimensional cohesive elements (Abaqus COH3D8 [39])) was also implemented at the midplane in the un-cracked region. A minimum of ten cohesive elements in the cohesive zone length (CZL) are guaranteed for these models. Likewise, the greatest dimension of the elements varies from $0.83 \mathrm{~mm}$ in the un-cracked zone to $0.26 \mathrm{~mm}$ close to the pre-crack. The loading blocks were not modeled and the DCBs were only simulated from the loading line onwards (i.e. according to Fig. 3, only from $a_{0}$ ). The boundary conditions were applied at the bottom (pinned condition) and top edges (out-of-plane opening displacement condition). The engineering constants used to define the bulk material are listed in Table 4 and as for the plates, the nonlinear geometry (NLGEOM) 
option was used to account for large deformation effects. One FE model for each of the DCB configurations presented in Table 4 was performed.

\subsection{Cohesive zone modeling}

In Mode I delamination, cohesive elements are defined by their "traction-separation" response where the normal traction, $\sigma$, over the fracture process zone (FPZ) is a function of the local crack-opening displacement $\delta$ as illustrated in Fig. 6-7. Once the FPZ is fully developed, the maximum crack opening, $\delta_{f}$, is achieved and tractions vanish. Two different damage processes can be distinguished in composite materials in the presence of fiber-bridging. The first is related to damage and micro-fractures of the matrix (epoxy) in the process zone in front of the crack tip (DP1 in Fig. 6) while the second corresponds to the fiber-bridging behind the crack (DP2). As investigated in literature $[18,30]$, the traction separation law suitable for the simulation of delamination under the effect of fiber-bridging is the result of the combination of i) the traditional cohesive law, where damage evolves according to a linear softening (from damage initiation traction, $\sigma_{c}$, to the maximum bridging traction, $\sigma_{\max }$ ), and ii) the bridging law, where damage evolves according to bridging stress functions (from $\sigma_{\max }$ to zero tractions). The former corresponds to the initial part of the traction-separation law in Fig. 6 (in orange) and the latter to the second part (in blue). The traction-separation law used in this paper to define the behavior of the cohesive elements is shown in Fig. 7. The first part of the law (in orange) is attributed to the initial damage growth in the DP1 zone and the area under this bilinear part equals the strain energy release rate (SERR) at the crack tip, $G_{t i p}$, corresponding to the energy required for crack initiation. The second part (in blue) corresponds to the SERR due to the fiberbridging, $G_{b r}$. The addition of these two SERR values equals the total area under the tractionseparation law, which will be referred hereafter as $G_{t o t}$ (i.e. $G_{t o t}=G_{t i p}+G_{b r}$ ). The bridging tractions are given by [18]:

$\sigma_{b r}(\delta)=e^{-\gamma \sqrt{\delta-\delta_{1}}} \sigma_{\max }\left(1-\sqrt{\frac{\delta-\delta_{1}}{\delta_{f}-\delta_{1}}}\right), \delta_{1} \leq \delta \leq \delta_{f}$

where $\delta$ is the crack-opening displacement (COD), $\sigma_{\max }$ and $\delta_{1}$ are the maximum bridging traction and the corresponding COD and $\delta_{f}$ is the COD at the end of the bridging zone. Likewise, $\gamma$ is the parameter governing the bridging tractions' profile. As can be observed in the zoom of the bridging tractions in Fig. 7, the smaller the value of $\gamma$ (for fixed values of $\sigma_{\max }$ and $\delta_{f}$ ) the greater the area under the curve, and thus the greater the value of $G_{b r}$. The overall traction-separation response is defined as:

$\sigma=(1-D(\delta)) K_{0} \delta$ 
$D(\delta)=\left\{\begin{array}{cc}0 & \text { for } 0 \leq \delta \leq \delta_{c} \\ 1-\frac{\alpha \delta+\beta}{K_{0} \delta} & \text { for } \delta_{c} \leq \delta \leq \delta_{1} \\ 1-\frac{\sigma_{b r}}{K_{0} \delta} & \text { for } \delta>\delta_{1}\end{array}\right.$

where $\sigma$ is the general cohesive traction, $D$ is the damage, $K_{0}$ is the initial cohesive stiffness and $\alpha$ and $\beta$ are:

$\alpha=\frac{\sigma_{c}-\sigma_{\max }}{\delta_{c}-\delta_{1}}$

$\beta=\sigma_{c}-\alpha \delta_{c}$

where $\sigma_{c}$ and $\delta_{c}$ are the corresponding values of the traction and COD for damage initiation.

The presented traction-separation law was implemented in the FE model by means of a user material subroutine (UMAT) written in FORTRAN programming language. The damage definition $(D(\delta))$ was changed according to the formulation presented (Eq. 2-5). Details and theoretical background of the formulation of the original UMAT can be found in [41, 42].

\section{Experimental results and discussion}

\subsection{Experimental results for laminated plates}

The experimental results previously obtained for the two laminated plates under study in this investigation (CFM) are summarized in the following. In Fig. 8 the load vs displacement and average crack-length vs displacement curves are shown for both CFM plates.

In Fig. 8 it can be observed that, even after crack initiation, a continuously increasing loadopening displacement behavior was obtained up to specimen failure. This behavior differed from the load-displacement behavior in fracture mechanics experiments such as DCB, where the load tends to decrease during crack propagation, due to the different crack growth pattern observed in each system. In a DCB (or any beam-like fracture experiment) the length of the crack front remains almost constant and perpendicular to the direction of propagation for each increment in the length of the crack and therefore the cracked area grows proportionally to the crack length. However, in a 2D fracture experiment, the crack front (perimeter of the concentric circles) increases for each increment in the radial direction, causing a non-proportional growth of the crack area in relation to the propagation distance and forcing the load to increase to maintain the crack propagation (i.e. more energy is needed to advance the crack by the same increment). This difference in the growth of the area of the crack between the two configurations is presented in Fig. 9 using the numerical results of the plate and of the DCB40(1-2). The crack areas represented in this figure correspond to propagated crack areas and therefore the area of the pre-cracks is not considered. To compare the results, the crack area in 
the DCB was calculated by considering a width equal to the length of the perimeter of the precrack in the plate $(2 \pi \cdot 90 \mathrm{~mm})$ (see Fig. 9). In the horizontal axis two values can be read: crack length for the DCB and crack radius for the plate. It can be observed that the growth of the crack area is greater in the plate than in the equivalent DCB and how this difference increases as the crack propagates.

The curves illustrating the crack area vs the compliance (calculated as $\delta / P, \delta$ being the opening displacement and $P$ the load) of the plates are shown in Fig. 10. The area was calculated for each increment as the area between the crack front and the loading line, i.e. a $35-\mathrm{mm}$ radius circle passing through the center of the screws that constitute the loading points (see Fig. 1). Based on the compliances, two main different regions could be differentiated (A and B in Fig. 10). In region $A$, a decreasing behavior of the compliance was observed (i.e. stiffening of the plate) down to a minimum value (transition point, TP). From the TP onwards (Region B), the compliance started to increase (i.e. softening of the plate). The decreasing behavior of region A in the curve of the CFM.2 plate was however less accentuated than for the CFM.1 plate.

The initial ascending branch of the compliance curve immediately after crack initiation was attributed to an initial readjustment between the loading system and the specimen. The changes in the stiffness were caused by three different mechanisms activated during the opening of the plates: stretching, fiber-bridging and crack propagation. Two curvatures could be distinguished as the plate opened: the radial and the circumferential. The frame-like boundary of the plates, i.e. the undamaged zone around the crack which did not deform and thus acting like a frame, led to the radial stretching of the out-of-plane deforming open part of the plates. Likewise, as the crack was embedded in the plate, the elongation in the circumferential direction during the out-of-plane deformation was also constrained, causing the corresponding circumferential stretching. Therefore, the plate was subjected to a biaxial stretching and thus a biaxial stiffening effect. Once the crack started propagating, the other two mechanisms were activated: the fiberbridging, contributing to the stiffening of the plate, and the crack propagation itself, causing the softening of the system. The stiffening mechanisms prevailed over the softening up to the TP. Beyond the TP, the softening was the dominant mechanism. Typically, for a standard (1D) fracture experiment, crack propagation is the dominant mechanism after crack initiation, always leading to an upward trend of the compliance curve. Further discussion and details can be found in [35]. 


\subsection{Experimental results for DCB specimens}

The experimental load-displacement responses of the new set of DCB specimens described in Section 2.2 are presented in Fig. 11. Typical curves of this type of specimens (increase of the load up to a maximum followed by decrease) can be observed. Representative side views of the fiber-bridging for two specimens are presented in Fig. 12. For the calculation of the total SERR of the specimens, $G_{t o t}$, the experimental compliance method (ECM) was used. The $G_{t o t}$ derived from the experiments is the sum of the SERR at the crack tip, $G_{t i p}$, and the SERR due to the fiber-bridging, $G_{b r}$. The expression used for the calculation based on the experimental compliance was the following [43]:

$G_{t o t}=G_{t i p}+G_{b r}=\frac{P^{2}}{2 b} \frac{\partial C}{\partial a}$

where $P$ is the load, $b$ is the specimen width, $C$ is the compliance and $a$ is the crack length. The R-curves obtained for all the DCB specimens are shown in Fig.13. According to these curves, values of $400 \mathrm{~J} / \mathrm{m}^{2}$ and $2000 \mathrm{~J} / \mathrm{m}^{2}$ respectively were assigned to $G_{\text {tip }}$ and $G_{\text {tot }}$. The length of the fiber-bridging observed in the side views of the specimens (see Fig. 12) are in good agreement with the lengths inferred from the R-curves (i.e. the crack length corresponding to the starting point of the plateau of the crack propagation value, see Fig.13). A value of $\sim 10 \mathrm{~mm}$ for the fiber-bridging length was obtained along with a maximum $\mathrm{COD}, \delta_{f}$, of $\sim 1.25 \mathrm{~mm}$ (see Fig. 12). Likewise, as can be observed in Fig. 13, similar R-curves were obtained (considering the typical scatter) regardless of the width.

\section{Numerical results and discussion}

\subsection{DCB specimens}

The traction-separation law described in Section 3.3 was implemented in the cohesive elements of the FE model developed for the DCB specimens presented in Section 3.2. The experimentally obtained SERR values of $G_{t i p}=400 \mathrm{~J} / \mathrm{m}^{2}$ and $G_{t o t}=2000 \mathrm{~J} / \mathrm{m}^{2}$ (i.e. $G_{b r}=1600 \mathrm{~J} / \mathrm{m}^{2}$ ) and the maximum $\operatorname{COD}\left(\delta_{f}=1.25 \mathrm{~mm}\right)$ were assigned. According to [44, 45], the maximum traction for damage initiation was assumed to be equal to $30 \%$ of the tensile strength of the matrix ( $84 \mathrm{MPa}$, manufacturer data [37]), i.e. $\sigma_{c}=25.2 \mathrm{MPa}$. The initial cohesive stiffness, $K_{0}$, was taken as being equal to $10000 \mathrm{MPa} / \mathrm{mm}$ [41] and the resulting value of $\delta_{1}$ was $0.027 \mathrm{~mm}$. The values of the maximum bridging traction, $\sigma_{\max }$, and the bridging traction decay ratio, $\gamma$, were estimated iteratively to fit the numerical with the experimental load-displacement responses. Corresponding values of $\sigma_{\max }=5 \mathrm{MPa}$ and $\gamma=0.46$ were obtained to maintain the $G_{\text {tot }}$ equal 
to $2000 \mathrm{~J} / \mathrm{m}^{2}$. The same traction-separation law was used for all DCB specimens and is presented in Fig. 14. The numerical load-displacement curves obtained for the new set of DCB specimens are shown in Fig. 11. As can be observed, the experimental curves are in good agreement with the numerical prediction.

As mentioned in Section 2.2, a wide range of DCB specimen widths was selected in order to study the influence of the width on the total SERR. As previously described, the reinforcement is composed of long continuous glass filaments randomly distributed in-plane and although no influence of the width has been reported in the literature for unidirectional-fiber DCB specimens, a possible effect of the anchorage length (which increases with width) on the fiberbridging behavior was considered. However, in view of the experimental R-curves presented in Fig. 13 and the validity of the same bridging parameters for all specimens (see numerical loaddisplacement curves in Fig. 11), it can be concluded that the width of the DCB specimens has no influence on the fracture results, at least in the range investigated here. Therefore, the development of the fiber-bridging has been proved to be independent of the length of the fibers in mat-like reinforcements.

\subsection{Laminated plates}

The same type of traction-separation law was implemented in the cohesive elements of the FE model of the plates. Initially, the same traction-separation law obtained for the DCB specimens was used (see Fig. 14), the total value of the SERR being therefore equal to $G_{t o t}=2000 \mathrm{~J} / \mathrm{m}^{2}$. However, the numerical load-displacement response obtained with these values did not correspond to the experimental curves, leading to an underestimation of the experimental load, as shown in Fig. 15. In order to better approach the experimental behavior, a fitting process was carried out. The values of $K_{0}, G_{t i p}, \sigma_{c}$ and $\sigma_{\max }$ (typically matrix-dominated values) were kept constant and the same as those obtained from the DCB specimens. The adjustment of the law was accomplished by fitting the value of $G_{b r}$ and therefore modifying the values of $\gamma$ and $\delta_{f}$. The selected values that allowed the FE model to predict the experimental behavior were $\gamma=0.01$ and $\delta_{f}=1.58 \mathrm{~mm}$ which lead to a $G_{b r}$ value of $2600 \mathrm{~J} / \mathrm{m}^{2}$ and therefore to a $G_{t o t}$ value of $3000 \mathrm{~J} / \mathrm{m}^{2}$. The obtained traction-separation law is presented in Fig. 14. The revised numerical load-displacement and crack length-displacement curves are shown in Fig. 16. A very good agreement with the experimental results was obtained. The numerically determined initiation of the crack (see Fig. 16) was taken as the point where the first cohesive element reached a COD equal to $\delta_{1}=0.027 \mathrm{~mm}$ (see Fig. 7 and Fig. 14) and therefore the point where the SERR equaled $G_{t i p}$. It can be observed that the numerical initiation value was between the experimental 
initiation values of the two plates, proving that the initial part of the traction-separation law (up to $\delta_{1}$ in Fig. 7) is independent of any size or geometry change. The second part of the law (from $\delta_{1}$ to $\delta_{f}$ in Fig. 7) was however the varying part, proving that the fiber-bridging is not a material property and is likely to vary under different configurations of the same material system.

In Fig. 10 the numerical compliance vs crack area is shown, also presenting good agreement with the trend of the experimental curves. The initial increasing behavior of the experimental compliance was not reproduced in the numerical results, proving that its attribution to local slipping effects was correct. The TP (see Section 4.1) is indicated in both the experimental and numerical curves. As for the initiation value in Fig. 16, the numerical TP was between the two experimental results, also obtaining a good agreement with the latter.

The numerically derived R-curve is shown in Fig. 17. The numerical value of the crack area at the TP in Fig. 10 coincides with the numerical value of the fully developed bridging area in the numerical R-curve (see Fig. 17). Consequently, with the value of the area at the TP obtained from the compliance vs crack area curve, the value of the bridging area of the plate can be directly obtained. The numerical value of this propagated area was $\sim 29600 \mathrm{~mm}^{2}$ which corresponded to a propagated radial length measured from the front of the pre-crack of $\sim 13.2$ mm. As described in Section 4.1, the TP corresponds to the change in behavior of the compliance when the general softening due to the propagation of the crack dominated over the stiffening mechanisms (stretching and fiber-bridging). Therefore, as a result of the identification of the fully developed bridging area with the TP, any decrease or increase in the bridging area would lead the compliance vs crack area curve moving to the left or right respectively (Fig. 18). The initiation point, proved to be a material property, would not change. Moreover, this correspondence between the TP and the full development of the fiber-bridging justifies the change of the increasing load-displacement curve from non-linear to linear (see TPs in Fig. 16). Before the TP the stiffening mechanisms were dominant and therefore the load increased non-linearly. However, the TP was the point where the softening started to dominate and the fiber-bridging was fully developed, achieving an equilibrium between stiffening and softening and entering the plateau of the R-curve (Fig. 17). Therefore, the linearization of the increasing load (beyond the TP) can be related to the stabilization of the crack propagation.

The fitting of the traction-separation law revealed a dependency between the slope of the load after the TP and the value of $G_{b r}$ (controlled by the parameters $\gamma$ and $\delta_{f}$ ) and therefore between the values of TP and $G_{t o t}$. The slope obtained with a value of $G_{t o t}=2000 \mathrm{~J} / \mathrm{m}^{2}$ was 0.213 (see 
Fig. 15) while the slope obtained with a value of $G_{t o t}=3000 \mathrm{~J} / \mathrm{m}^{2}$ was 0.273 (see Fig. 16). Thus the greater the value of $G_{t o t}$, the greater the value of the slope. Likewise, the numerical slope was also between the two experimental values (0.266 and 0.294).

The total value of the SERR obtained from the FEM of the plates was $50 \%$ higher than the total SERR derived from the DCB specimens, increasing from $2000 \mathrm{~J} / \mathrm{m}^{2}$ to $3000 \mathrm{~J} / \mathrm{m}^{2}$. This increase in the $G_{t o t}$, and thus in the R-curve, was directly related to the difference in stiffness between the DCB specimens and the plates. In terms of flexural stiffness, the plate was several times stiffer than any of the investigated DCB specimens. Furthermore, the biaxial stretching of the deformed part of the plate (radially and circumferentially) resulted in a biaxial "stress stiffening" effect. Consequently, more fiber-bridging than in the DCB specimens developed in the plates. Due to the in-plane isotropy of the plate, the opening of the crack was the same all along its contour (i.e. circumferential concentric growth) restraining the fiber-bridging to develop only in the radial direction, in spite of the bi-dimensionality of the crack propagation. The fiber-bridging length and $\delta_{f}$ were higher in the plates than in the DCB specimens (13.2 vs $10 \mathrm{~mm}$ and $1.58 \mathrm{vs} 1.25 \mathrm{~mm}$ respectively). The rate of decay of the bridging tractions, $\gamma$, was considerably smaller in the plates ( 0.01 vs 0.46 in the DCB specimens) and became the main parameter responsible for the increase of the $G_{b r}$ and thus of the $G_{t o t}$. The lower the rate of decay, the lower the reduction in the bridging traction for a specific crack opening along the bridging zone (see Fig. 7). Therefore, the increase of the stiffness in the plates contributed to the development of a fiber-bridging capable of maintaining higher bridging tractions during the opening of the crack.

The difference in the amount of fiber-bridging developed in the DCB specimens and the plates was also determined by comparing the experimental and numerical load-displacement results obtained for DCB-25-3 (cut from CFM.1), presented in Fig. 19. For the sake of comparison, the experimental and numerical results obtained for the other DCB specimens of the same width (DCB-25 (1-2) were also added in Fig. 19. The numerical response of DCB-25-3 was obtained by implementing the same traction-separation law as for the rest of the DCB specimens but, resulted in an underestimation of the load. Typically, for standard fracture load-displacement curves, two different regions can be identified regarding the shape of the traction-separation law [16]. The first region (region 1 in Fig. 19) depends on the shape of the traction-separation law and corresponds to the development of the fiber-bridging. The second (region 2 in Fig. 19), once the fiber-bridging is fully developed, depends exclusively on the value of $G_{t o t}$ (i.e. the total area under the traction-separation law). This second region can be clearly identified in Fig. 19 
for DCB-25-3 as the region where the numerical results match the experimental results. It is also evident that the $G_{t o t}$-dominated region of DCB-25-3 overlapped the same region in DCB25 (1-2) (i.e. both $G_{t o t}$ values were the same). The length of the radius of the fully developed bridging area in the plates was found to be $13.2 \mathrm{~mm}$ and the length of the propagated crack (measured from the end of the pre-crack) of DCB-25-3 cut from CFM.1 was $22.5 \mathrm{~mm}$. Therefore, a 13.2-mm bridging length was already present in DCB-25-3 before the experiment. However, as the DCB opened, the new fiber-bridging was developing up to the bridging length corresponding to the DCB configuration $(\sim 10 \mathrm{~mm})$ and consequently, a drop in the load was registered (see Fig. 21) as a result of the loss in the amount of fiber-bridging.

\subsection{Influence of shape of traction-separation law}

A different type of traction-separation law was implemented in the FE models to compare the influence of the shape of the law on the load-displacement response of the DCB specimens and the laminated plates. In both cases, a law with a linear softening (see Fig. 14) from $\sigma_{c}$ onwards, without explicitly taking into account fiber-bridging, was selected for the comparison. The value of the $G_{t o t}$ was the same as for the traction-separation laws obtained with fiber-bridging (i.e. $2000 \mathrm{~J} / \mathrm{m}^{2}$ for the DCB and $3000 \mathrm{~J} / \mathrm{m}^{2}$ for the plate). The chosen DCB specimen was the DCB-100-2 and the corresponding results are presented in Fig. 20. It can be observed how the $G_{t o t}$-dominated regions (region 2) of both overlapped, similarly to what occurred in Fig. 19 with the DCB-25 specimens while initially (region 1) their behavior differed due to the differences in the shape of the traction-separation law. However, a different behavior was obtained from the plate (see Fig. 21). In this case, instead of an overlapping of the $G_{t o t}$-dominated regions, parallel curves were obtained, as the value of $G_{t o t}$ is the same. Consequently, the shape of the traction-separation law chosen to simulate the fracture behavior in plates affected not only the load-displacement results during the development of the bridging area (i.e. up to the TP) but also the rest of the curve, leading to the overestimation of the load in this case. This behavior proves the previously discussed relationship between the slope of the load-displacement curve after the TP and the value of $G_{t o t}$.

\section{Conclusions}

A numerical investigation of the $2 \mathrm{D}$ in-plane crack propagation in laminated plates with an embedded circular pre-crack was carried out in order to simulate the fracture behavior of the same plates that were experimentally investigated in a previous work [35]. Additional DCB experiments were performed to study the transition from 1D to 2D crack propagation scenarios. Three-dimensional FE models were developed to simulate the exhibited experimental fracture 
behaviors in both experimental configurations and cohesive elements were used to model the FPZ and a detailed analysis of the results was presented. The following conclusions can be drawn from this work:

1. The selected shape of the traction-separation law was able to model the fracture behavior of the plates, reproducing the trend in the behavior shown in the experimental load vs displacement and compliance vs crack area curves. By calibrating the law to fit the experimental and the numerical values, the total SERR and fiber-bridging values of the plates were determined.

2. The stress stiffening of the plates (due to the stretching) together with the increase in the flexural stiffness (from beam to plate) led to an increase of the developed fiberbridging area, causing a 50\% increase of the total SERR compared to the total SERR obtained from the DCB specimens. Taking into account the stiffness effects on the fracture mechanisms, more efficient damage-tolerant structural designs can be developed for large-scale bridging scenarios.

3. The stiffness variations of the plates were reflected in the compliance vs crack area curves, which exhibited first a decreasing behavior down to a minimum (transition point) after which it started to increase. This transition point represented the threshold between the stiffening and softening mechanism predominance.

4. The fully developed fiber-bridging area in the plates was correlated with the crack area at the transition point of the compliance vs crack area curves. Any increase or decrease in the amount of fiber-bridging would be reflected in this curve by anticipating or delaying the appearance of the transition point. Therefore, the area of the fiber-bridging can be directly obtained from the experimental compliance without any further experimental measurement.

5. The transition point was also correlated to the change from non-linear to linear increasing of the load, confirming the full development of the fiber-bridging and achievement of an equilibrium between the stiffening and softening mechanisms existing in the plates.

6. The slope of the load vs displacement curve in the linear part (i.e. after the transition point) was correlated to the total SERR. Higher slopes corresponded to higher total SERR values and vice versa. 


\section{Acknowledgments}

The authors wish to acknowledge the support and funding of this research by the Swiss National Science Foundation (Grant No. 200021_156647/1) and by the Mobility PhD Award granted by the doctoral program in Civil and Environmental Engineering (EDCE) of the École Polytechnique Fédérale de Lausanne (EPFL).

\section{References}

1. Bakis, C., Bank L. C., ASCE F., Brown V. L., ASCE M., Constenza E., Davalos J. F., ASCE A.M., Lesko J. J., Machida A., Rizkalla S. H., ASCE F., Triantafillou T. C., ASCE M. Fiber-reinforced polymer composites for construction-state-of-the-art review. Journal of Composites for Construction, 2002; 6(2): 73-87.

2. Williams J.G. On the calculation of energy release rates for cracked laminates. Int. J. Fract., 1988; 36(2): 101-119.

3. Brunner A.J.. Experimental aspects of Mode I and Mode II fracture toughness testing of fiber-reinforced polymer-matrix composites. Compt. Method. Appl. M., 2000; 185(2-4): 161-172.

4. Choi N.S., Kinloch A.J., Williams J.G.. Delamination fracture of multidirectional carbonfiber/epoxy composites under Mode I, Mode II and mixed-Mode I/II loading. J. Compos. Mater, 1999; 31(1): 73-100.

5. Benzeggagh, M.L., Kenane, M. Measurement of mixed-mode delamination fracture toughness of unidirectional glass/epoxy composites with mixed-mode bending apparatus. Compos. Sci. Technol., 1996; 56: 439-449.

6. ASTM D5528-13: Standard test method for mode I interlaminar fracture toughness for unidirectional fiber-reinforced polymer matrix composites, in Annual book of ATM standards: adhesive section 15.03 .

7. ASTM D6671/D6671M - 13e1: Standard test method for mixed mode I-mode II interlaminar fracture toughness for unidirectional fiber-reinforced polymer matrix composites, in Annual book of ATM standards: adhesive section 15.03.

8. Butler, R., Rhead, A.T, Liu, W., Kontis, N. Compressive strength of delaminated aerospace composites. Phil. Trans. R. Soc. A, 2012; 370:1759-1779.

9. Nilsson K.F., Thesken J.C., Sindelar P, Giannakopoulos A.E., Storakers B. A theoretical and experimental investigation of bucking induced delamination growth. J. Mech. Phys. Solids, 1993; 41(4): 749-782. 
10. Riccio A., Raimondo A., Di Caprio F., Scaramuzzino F. Delaminations buckling and growth phenomena in stiffened composite panel under compression. Part II: a numerical study. Journal of Composite Materials, 2014; 48(3); 2857-2870.

11. Rhead A.T., Butler R., Hunt G.W. Compressive strength of composite laminates with delamination induced interaction of panel and sublaminate bucking modes. Composite Structures, 2017; 171; 326-334.

12. Chen, Z.M., Krueger, R., Rinker, M. Facesheet/Core Disbond Growth in Honeycomb Sandwich Panels Subjected to Ground-Air-Ground Pressurization and In-Plane Loading. In: 11th International Conference on Sandwich Structures ICSS-11, Ft. Lauderdale, USA, March, 2016.

13. Rinker, M., Krueger, R., Ratcliffe, J. Analysis of an Aircraft Honeycomb Sandwich Panel with Circular Face Sheet/Core Disbond Subjected to Ground-Air Pressurization. NASA/CR-2013-217974, 2013.

14. Launey M.E., Ritchie R.O. On the fracture toughness of advanced materials. Adv. Mater., $2009 ; 21 ; 2103-2110$.

15. Canal L.P., Alfano M., Botsis J. A multi-scale based cohesive zone model for the analysis of thickness scaling effect in fiber bridging. Comp. Science and Tech., 2017; 139; 90-98.

16. Ortega A., Maimí P., González E.V., Trias D. Characterization of the translaminar fracture cohesive law. Composites: Part A, 2016; 91; 501-509.

17. Manshadi B.D., Farmand-Ashtiani E., Botsis J., Vassilopoulos A.P. An iterative analytical/experimental study of bridging in delamination of the double cantilever beam specimen. Composites: Part A, 2014; 61; 43-50.

18. Frossard G., Cugnoni J., Gmür T., Botsis J. Mode I interlaminar fracture of carbon epoxy laminates: effects of ply thickness. Composites: Part A, 2016; 91; 1-8.

19. Suo Z., Bao G., Fan B. Delamination R-curve phenomena due to damage. J. Mech. Phys. Solids, 1992; 40 (1): 1-16.

20. Manshadi B.D., Vassilopoulos A.P., Botsis J. A combined experimental/numerical study of the scaling effects on mode I delamination of GFRP. Comp. Science and Tech., 2013; $83 ; 32-39$

21. Sørensen B.F., Gamstedt E.K., Østergaard R.C., Goutianos S. Micromechanical model of cross-over fibre bridging-Prediction of mixed mode bridging laws. Mechanics of Materials, $2008 ; 40 ; 220-234$. 
22. Shaverdi M., Vassilopoulos A.P., Keller T. Modelling effects of asymmetry and fiber bridging on Mode I fracture behavior of bonded pultruded composite joints. Eng. Fract. Mech., 2013; 99; 335-348.

23. Cameselle-Molares A., Roohollah S., Shaverdi M., Vassilopoulos A.P., Keller T. Fracture mechanics-based progressive damage modelling of adhesively bonded fibre-reinforced polymer joints. Fatigue Fract. Eng. Mater. Struct., 2017; 40(12): 2183-2193.

24. Pappas G, Canal L.P., Botsis J. Characterization of intralaminar mode I fracture of AS4/PPS composites using inverse identification and micromechanics. Composites: Part A, 2016; 91; 117-126.

25. Barenblatt G.I. The formation of equilibrium crack during brittle fracture: general ideas an hypothesis, axially-symmetric cracks. J. Appl. Math. Mech., 1959; 23; 622-636.

26. Dugdale D. Yielding of steel sheets containing slits. J. Mech. Phys. Solids, 1960; 8(2); 100104.

27. Barenblatt G.I. The mathematical theory of equilibrium cracks in brittle fracture. Adv. Appl. Mech., 1962; 7; 55-129.

28. Launey M.E., Ritchie R.O. On the fracture toughness of advanced materials. Adv. Mater., $2009 ; 21 ; 2103-2110$.

29. Sørensen B.F., Jacobsen T.K. Large-scale bridging in composites: R-curves and bridging laws. Composites: Part A, 1998; 29A; 1443-1451.

30. Sorensen L., Botsis J., Gmür Th., Humbert L. Bridging tractions in mode I delamination: Measurements and simulations. Comp. Sc. and Tech., 2008; 68; 2350-2358.

31. Morel S., Lespine C., Coureau J.L., Planas J., Dourado N. Bilinear softening parameters and equivalent LEFM R-curve in quasibrittle failure. Inter. J. of Solids and Struct., 2010; $47 ; 837-850$.

32. Bao G., Suo Z. Remarks on crack-bridging concepts. Appl. Mech. Rev., 1992; 45(8); 355366.

33. Farmand-Ashtiani E., Cugnoni J., Botsis J. Specimen thickness dependence of large scale fiber bridging in mode I interlaminar fracture of carbon epoxy composite. Inter. J. of Solids and Struct., 2015; 55; 58-65.

34. Pappas G., Botsis J. Intralaminar fracture of unidirectional carbon/epoxy composite: experimental results and numerical analysis. Inter. J. of Solids and Struct., 2016; 85-86; 114-124.

35. Cameselle-Molares A., Vassilopoulos A.P., Keller T. Experimental investigation of twodimensional delamination in GFRP laminates. Eng. Fract. Mechs., 2017; under review. 
36. Owen's Corning Reinforcements Composite Solutions Guide.

$<$ http://www.ocvreinforcements.com/pdf/library/Composite_Solutions_Guide_100360_E _finalprintable.pdf $>$ (Accessed 26 March 2018).

37. Sika datasheet product. $<$ https://deu.sika.com/dms/getdocument.get/dd4b783e-bfa5-32e3a705-f9f548f6b326/Biresin_CR83_eng.pdf> (Accessed 19 October 2017).

38. Renart J., Blanco N., Pajares E., Costa J., Lazcano S., Santacruz G. Side Clamped Beam (SCB) hinge system for delamination tests in beam-type composite specimens. Comp. Sc. and Tech., 2011; 71; 1023-1029.

39. Abaqus Inc. Abaqus analysis user's manual, version 6.14-1. 2014. Providence, RI, USA.

40. Soto A., González E.V., Maimí P., Turon A., Sainz de Aja J.R., de la Escalera F.M. Cohesive zone length of orthotropic material undergoing delamination. Eng. Fract. Mechs., 2016; 159; 174-188.

41. Turon A., Camanho P.P., Costa J., Dávila C.G. A damage model for the simulation of delamination in advanced composites under variable-mode loading. Mechanics of Materials, 2006; 38(11): 1072-1089.

42. Turon A., Camanho P.P., Costa J., Renart J. Accurate simulation of delamination growth under mixed-mode loading using cohesive elements: Definition of interlaminar strengths and elastic stiffness. Composite Structures, 2010; 92(8): 1857-1864.

43. Anderson Ted. Fracture mechanics. $2^{\text {nd }}$ ed. Texas: CRP; 1995.

44. Heidari-Rarani M., Shokrieh M.M., Camanho P.P. Finite element modeling of mode I delamination growth in laminated DCB specimens with R-curve effects. Composites: Part B; 2013; 45; 897-903.

45. Camanho P.P., Dávila C.G., Ambur D.R. Numerical simulation of delamination growth in composite materials. NASA/TP-2001-211041. Hampton: NASA Langley Research Center; 2001. 


\section{Tables:}

Table 1. Material properties

\begin{tabular}{lcccc}
\hline Material & $\begin{array}{c}\mathrm{E} \\
(\mathrm{GPa})\end{array}$ & $\begin{array}{c}\mathrm{G} \\
(\mathrm{GPa})\end{array}$ & $\begin{array}{c}v \\
(-)\end{array}$ & $\begin{array}{c}\rho \\
\left(\mathrm{g} / \mathrm{cm}^{3}\right)\end{array}$ \\
\hline Epoxy resin & 2.96 & 1.30 & 0.35 & 1.14 \\
E-CR glass & 80.00 & 32.80 & 0.22 & 2.62 \\
\hline
\end{tabular}

Table 2. Description of GFRP laminated plates

\begin{tabular}{lcc}
\hline Plate type & No. of layers & $\begin{array}{c}\text { Dimensions (mm) } \\
\text { (width x height x avg. thickness) }\end{array}$ \\
\hline CFM.1 & 6 & $420 \times 420 \times 7.50$ \\
CFM.2 & 6 & $420 \times 420 \times 6.99$ \\
\hline
\end{tabular}

Table 3. Elastic properties of laminated plates

\begin{tabular}{lcccccc}
\hline & $\begin{array}{c}\mathrm{E}_{1}=\mathrm{E}_{2} \\
(\mathrm{GPa})\end{array}$ & $\begin{array}{c}\mathrm{E}_{3} \\
(\mathrm{GPa})\end{array}$ & $\begin{array}{c}\mathrm{G}_{12} \\
(\mathrm{GPa})\end{array}$ & $\begin{array}{c}\mathrm{G}_{13}=\mathrm{G}_{23} \\
(\mathrm{GPa})\end{array}$ & $\begin{array}{c}v_{12} \\
(-)\end{array}$ & $\begin{array}{c}v_{13}=v_{23} \\
(-)\end{array}$ \\
\hline $\begin{array}{l}\text { Estimated in [35] } \\
\text { (CFM.1) }\end{array}$ & 9.34 & 4.68 & 3.51 & 1.54 & 0.33 & 0.30 \\
\begin{tabular}{l} 
Used in FEM \\
\hline
\end{tabular} & $8.64^{*}$ & 4.68 & $3.25^{*}$ & 1.54 & 0.33 & 0.30 \\
\hline
\end{tabular}

* Updated values from the DCB test

Table 4. Geometrical and elastic properties of fracture mechanics (DCB) specimens

\begin{tabular}{|c|c|c|c|c|c|c|c|c|c|c|c|}
\hline & $\begin{array}{c}\mathrm{b} \\
(\mathrm{mm})\end{array}$ & $\begin{array}{c}\mathrm{h} \\
(\mathrm{mm})\end{array}$ & $\begin{array}{c}\mathrm{L} \\
(\mathrm{mm})\end{array}$ & $\begin{array}{c}\mathrm{m} \\
(\mathrm{mm})\end{array}$ & $\begin{array}{c}\mathrm{a}_{0} \\
(\mathrm{~mm})\end{array}$ & $\begin{array}{l}\mathrm{E}_{1}=\mathrm{E}_{2} \\
(\mathrm{GPa})\end{array}$ & $\begin{array}{c}\mathrm{E}_{3} \\
(\mathrm{GPa})\end{array}$ & $\begin{array}{c}\mathrm{G}_{12} \\
(\mathrm{GPa})\end{array}$ & $\begin{array}{c}\mathrm{G}_{13}=\mathrm{G}_{23} \\
(\mathrm{GPa})\end{array}$ & $\begin{array}{l}v_{12} \\
(-)\end{array}$ & $\begin{array}{c}v_{13}=v_{23} \\
(-)\end{array}$ \\
\hline DCB-25 \#1-2 & 25 & 7.64 & 250 & 42 & 50 & 9.22 & \multirow{4}{*}{4.64} & \multirow{4}{*}{3.47} & \multirow{4}{*}{1.54} & \multirow{6}{*}{0.33} & \multirow{6}{*}{0.3} \\
\hline DCB-25-3* & 25 & 7.5 & 220 & 12.5 & 42 & 8.64 & & & & & \\
\hline DCB-40 \#1-2 & 40 & \multirow{2}{*}{7.64} & \multirow{4}{*}{250} & 42 & 50 & ? & & & & & \\
\hline DCB-40 \#3-5 & 40 & & & 25 & 30 & 7.22 & & & & & \\
\hline DCB-60 \#1-3 & 60 & \multirow{2}{*}{6.80} & & 42 & 50 & 0 & (0) & & & & \\
\hline DCB-100 \#1-3 & 100 & & & 42 & 50 & 10.00 & 7.00 & (1) & 1.J & & \\
\hline
\end{tabular}

*Specimen cut from plate CFM.1, see Fig. 1 (b). 


\section{Figures:}

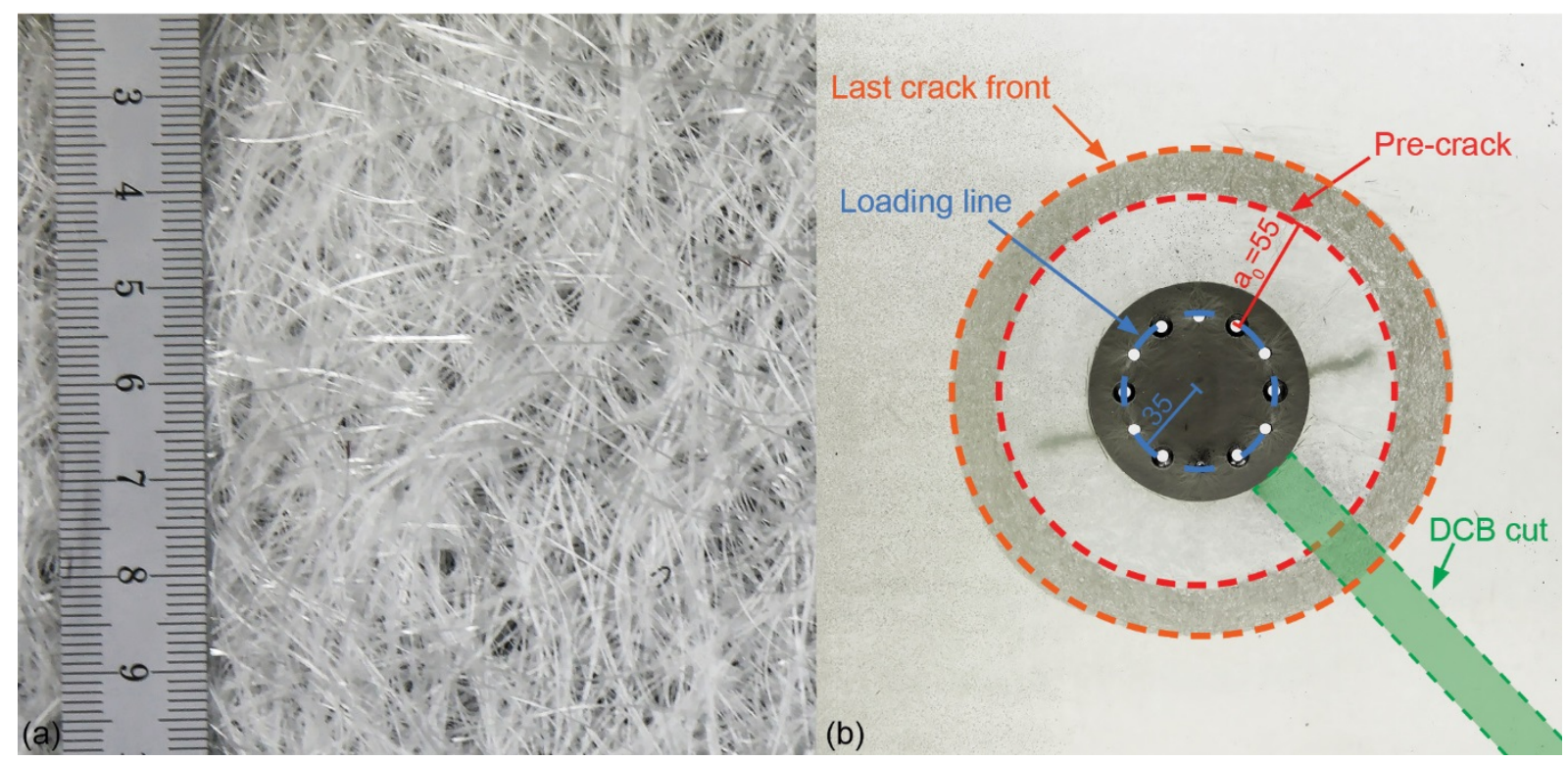

Fig. 1. Detail of glass fiber reinforcement (a) and crack propagation pattern in plate CFM.1 (b). Units in $\mathrm{mm}$.

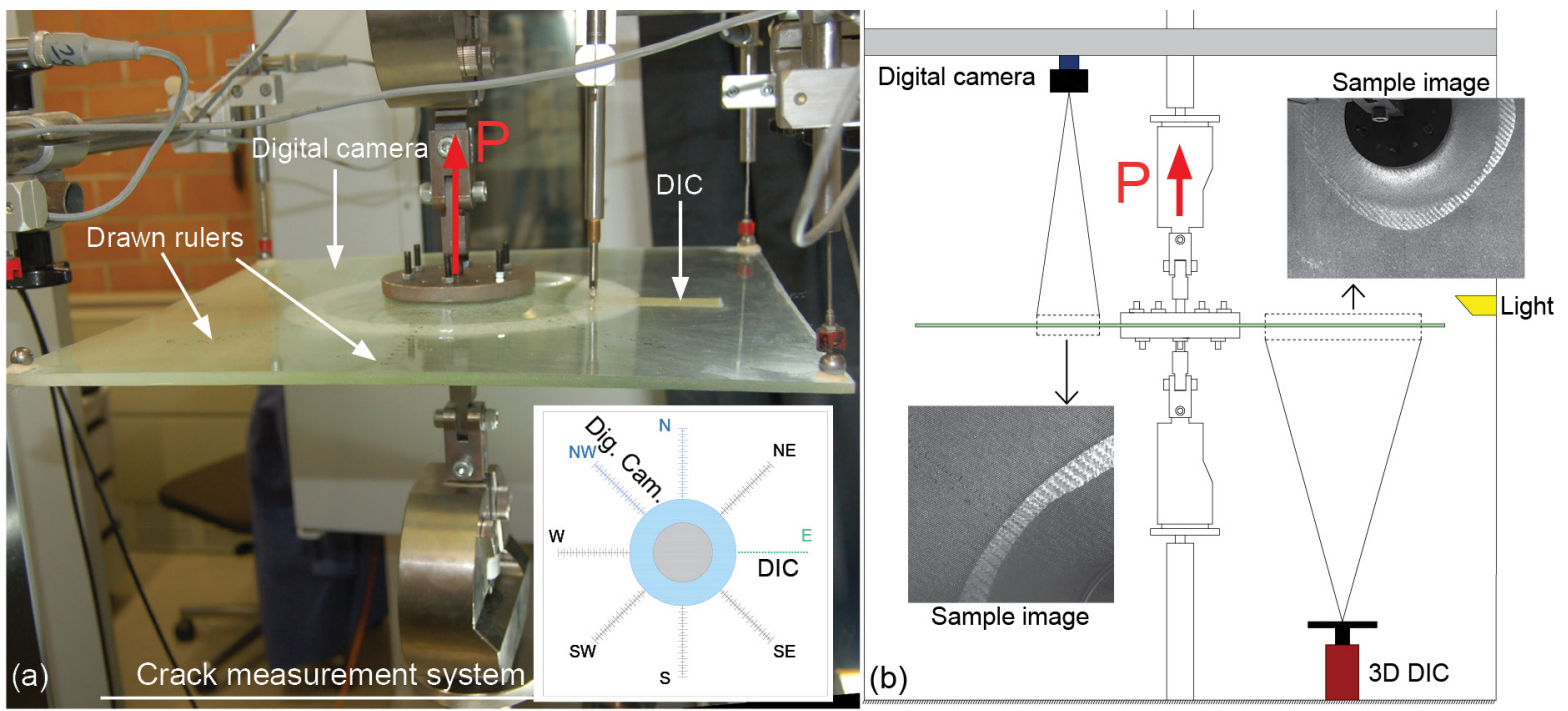

Fig. 2. Experimental set-up; (a) experiment on CFM.2 and crack measuring system layout; (b) layout of set-up 

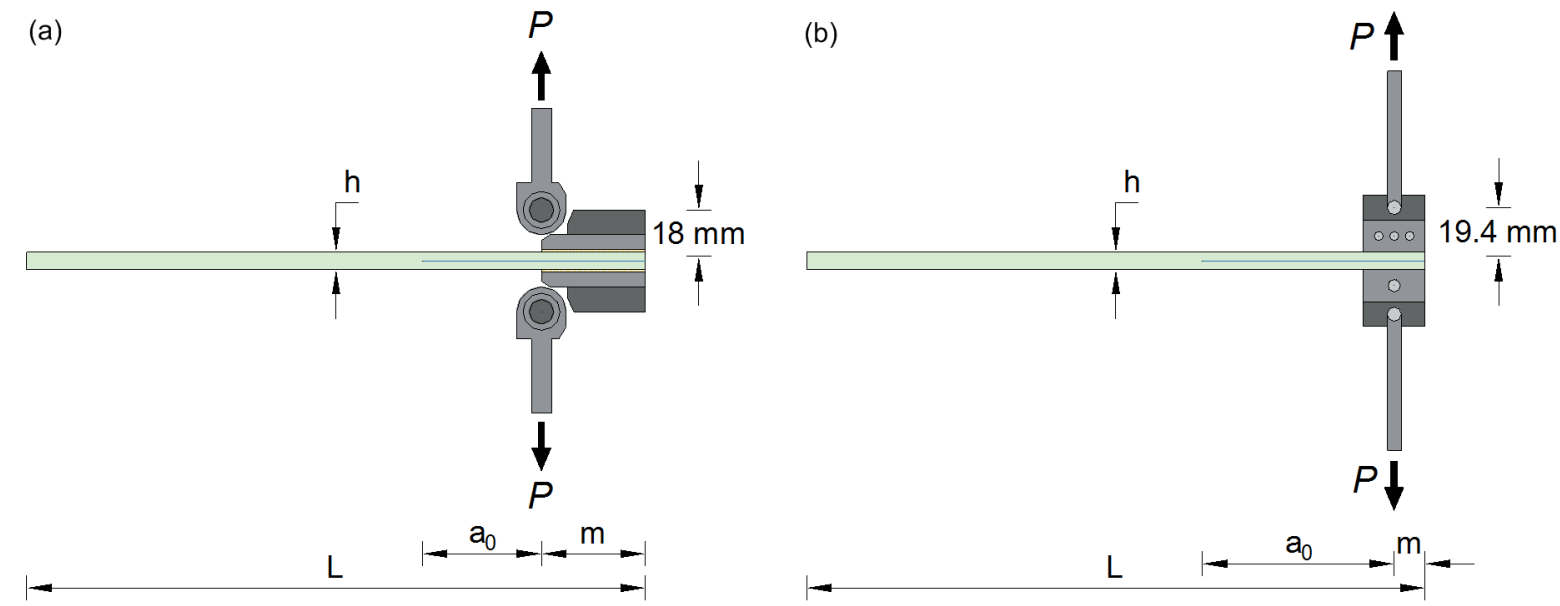

Fig. 3. DCB configurations; (a) in-house developed loading blocks (piano hinges); (b) patented [38] loading blocks; dimensions see Table 4

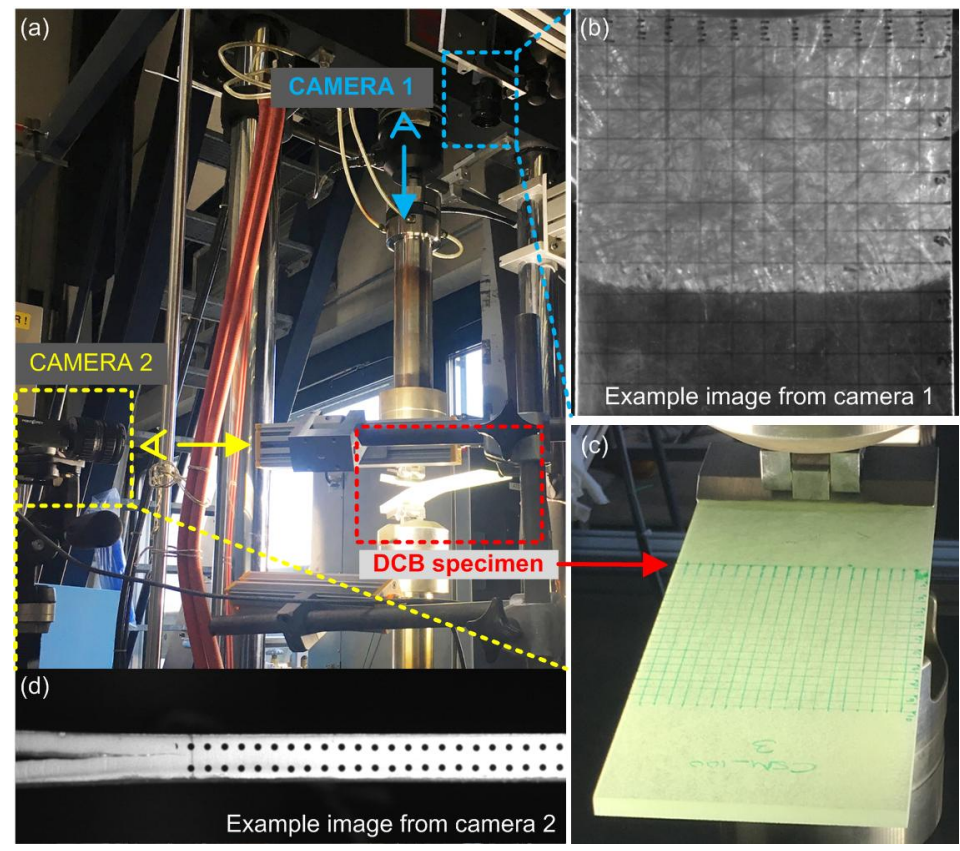

Fig. 4. DCB experimental set-up; (a) general view; (b) example of image from upper camera (Camera 1 in (a)); (c) DCB specimen with drawn grid ruler used for measurement of crack length; (d) example of image from side camera (Camera 2 in (a)) 


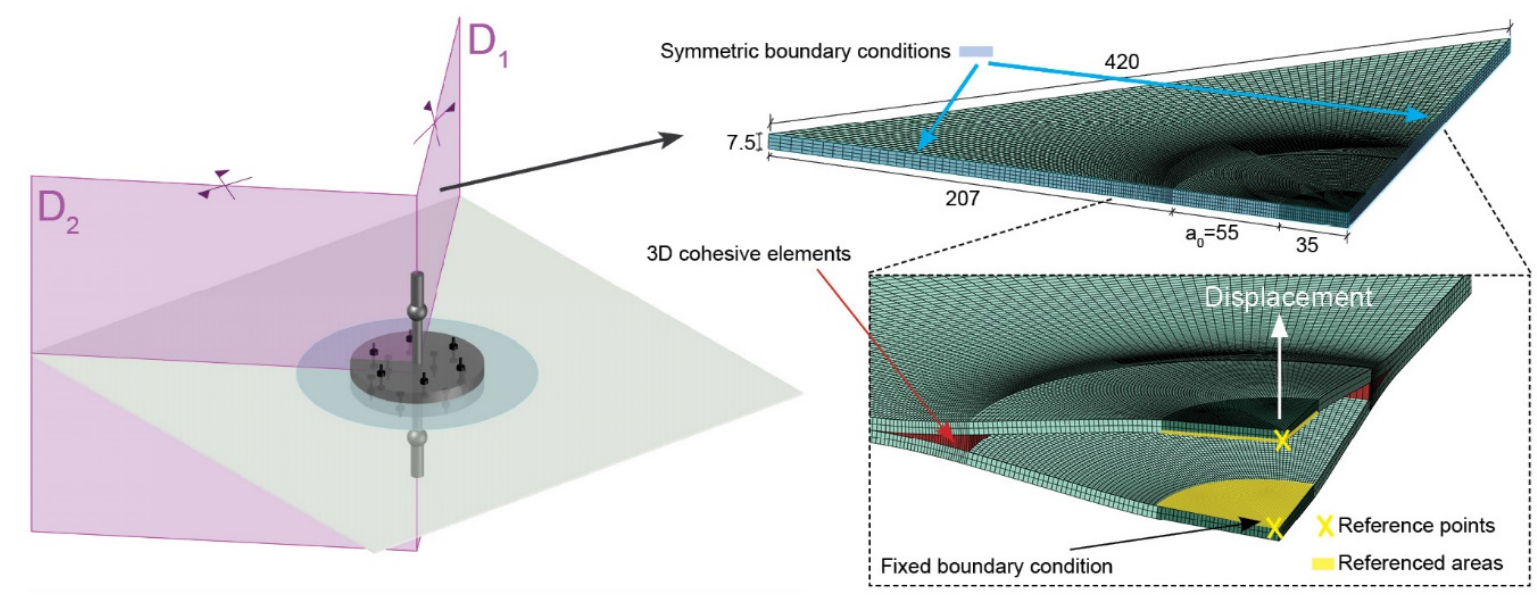

Fig. 5. Description of finite element model of laminated plate

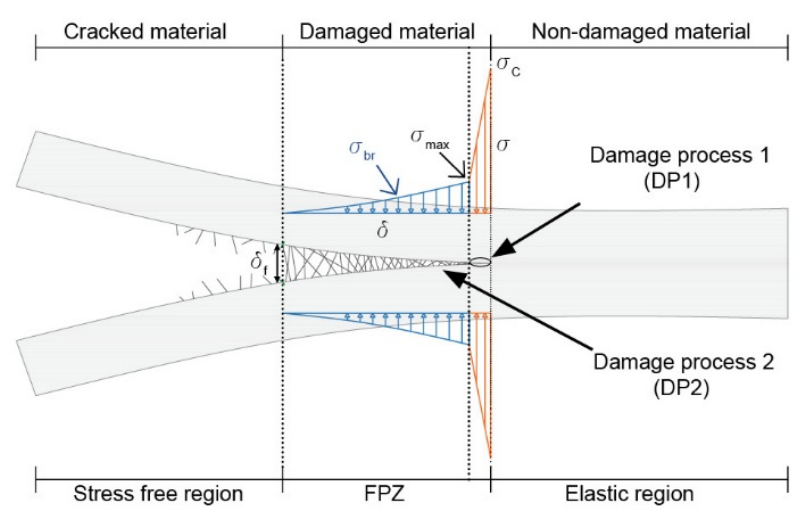

Fig. 6. Schematic general fracture section of Mode I delamination with fiber-bridging

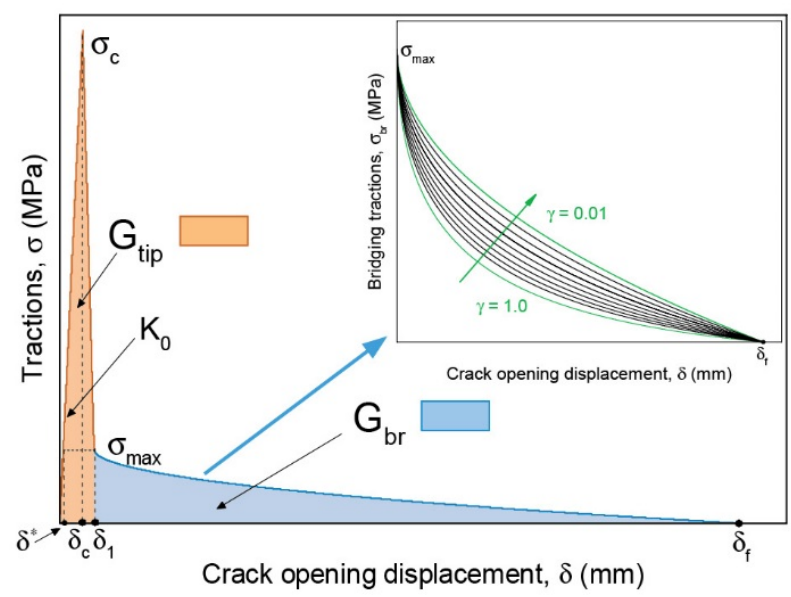

Fig. 7. Description of traction-separation law 


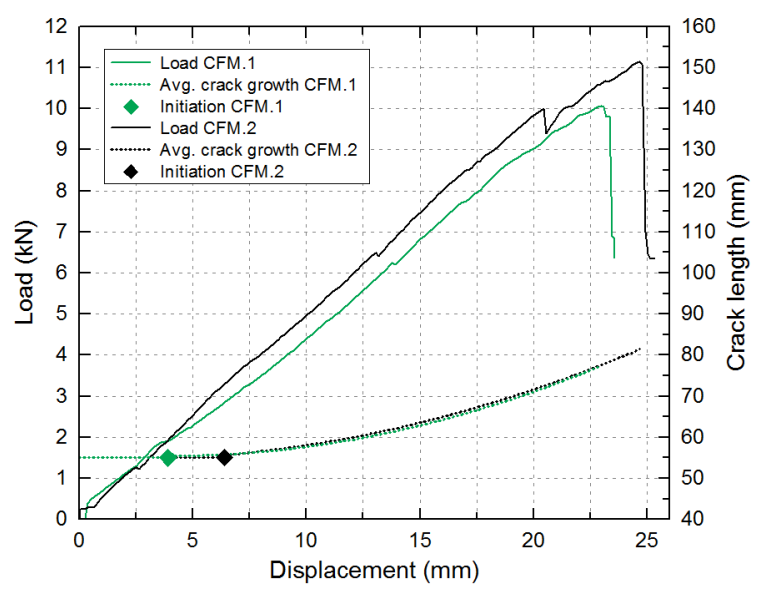

Fig. 8. Load and crack length vs displacement curves of CFM plates

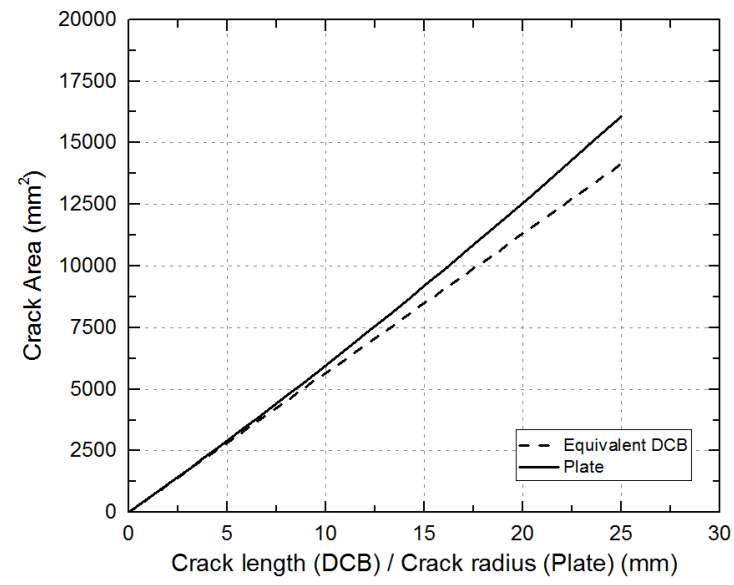

Fig. 9. Comparison of growth of crack area in a plate and equivalent DCB

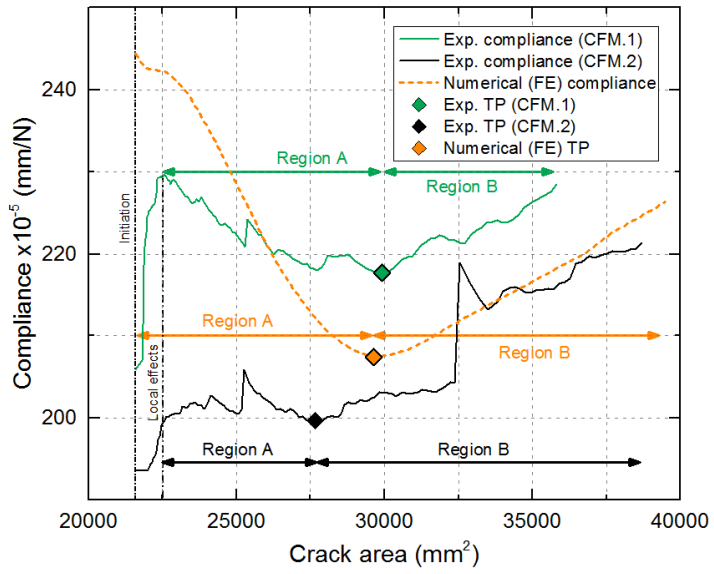

Fig. 10. Comparison of experimental and numerical crack area vs compliance of CFM plates 


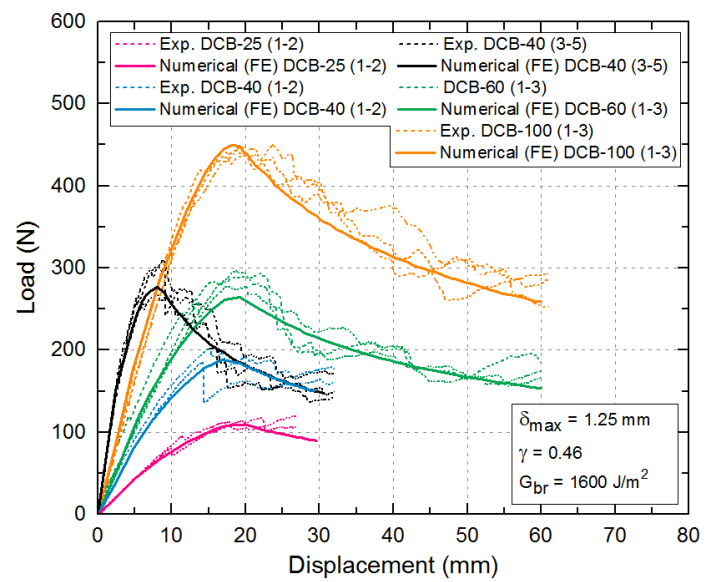

Fig. 11. Comparison of experimental and numerical load-displacement curves of DCBs

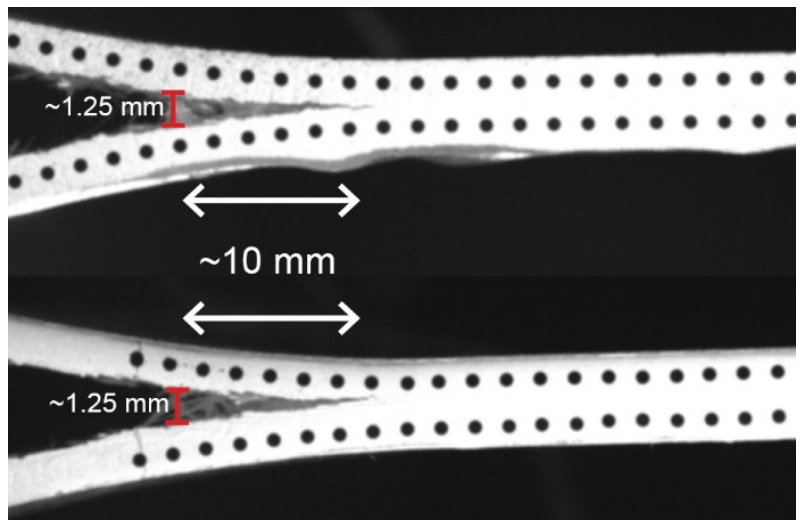

Fig. 12. Fiber-bridging zone; (a) DCB-25-2; (b) DCB-60-2

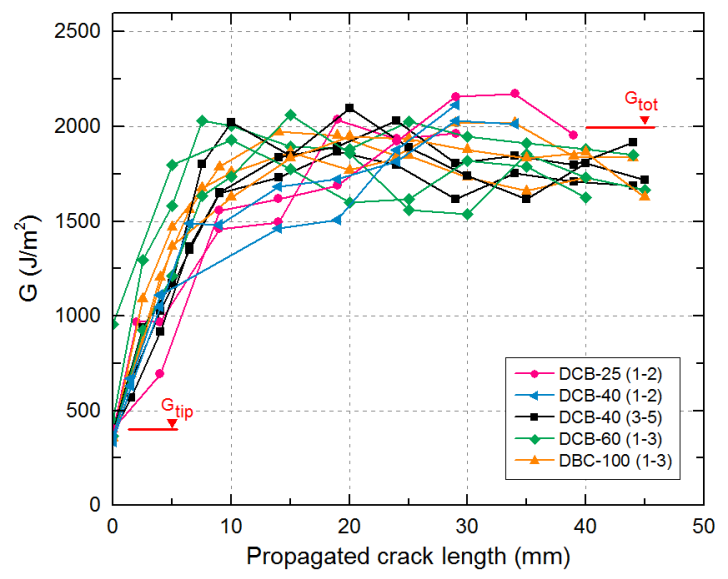

Fig. 13. Experimental R-curves obtained for DCB specimens 


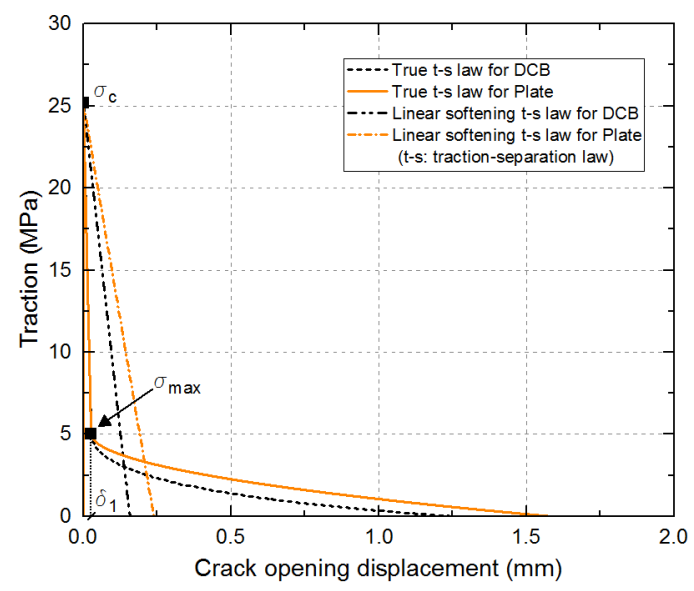

Fig. 14. Traction-separation curves used in numerical models

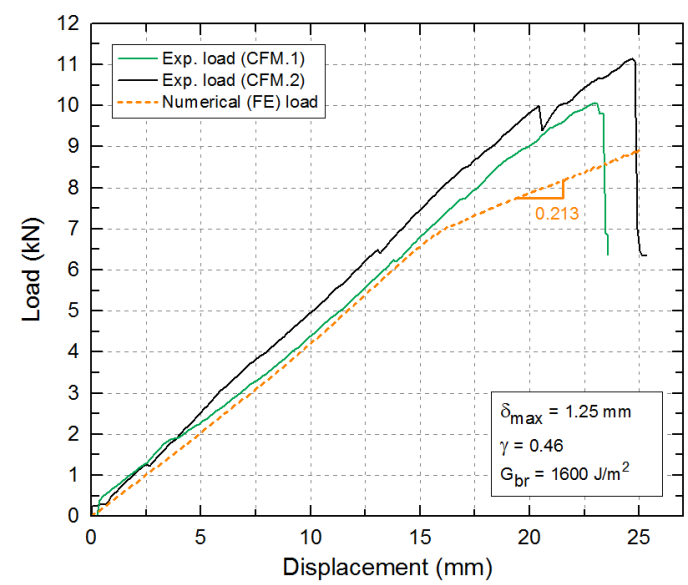

Fig. 15. Comparison of experimental and numerical load-displacement curves of CFM plates using cohesive parameters and total SERR obtained from DCBs

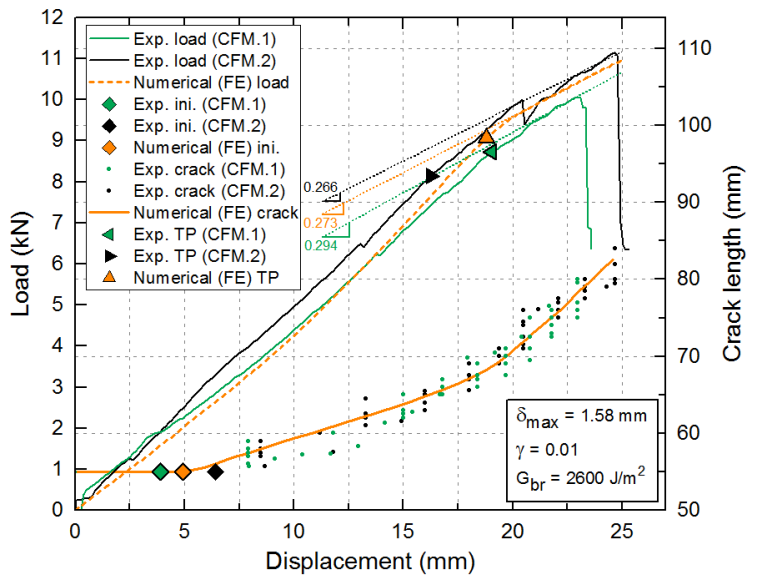

Fig. 16. Comparison of experimental and numerical load and crack lengths vs opening displacement curves of CFM plates 


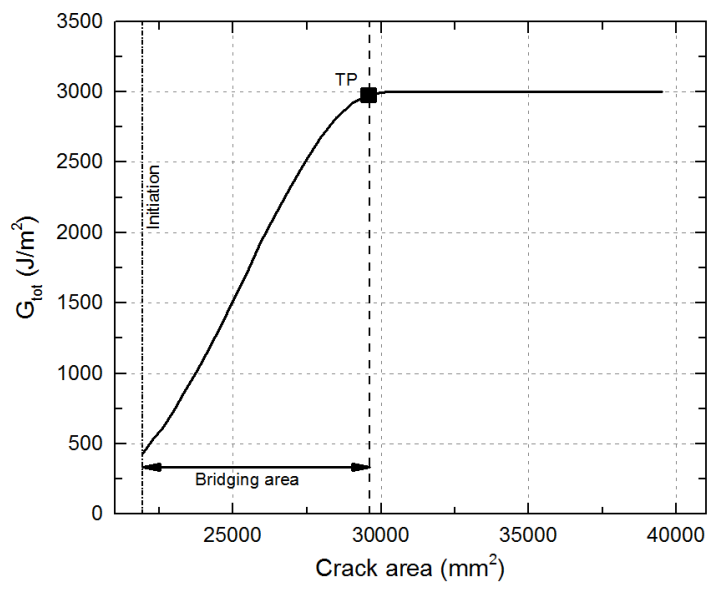

Fig. 17. Numerical R-curve of laminated plate

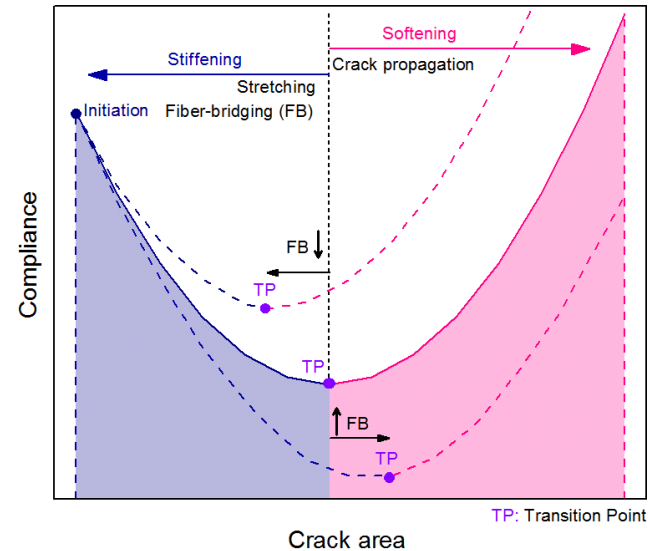

Fig. 18. Description of general behavior of crack area vs compliance curves

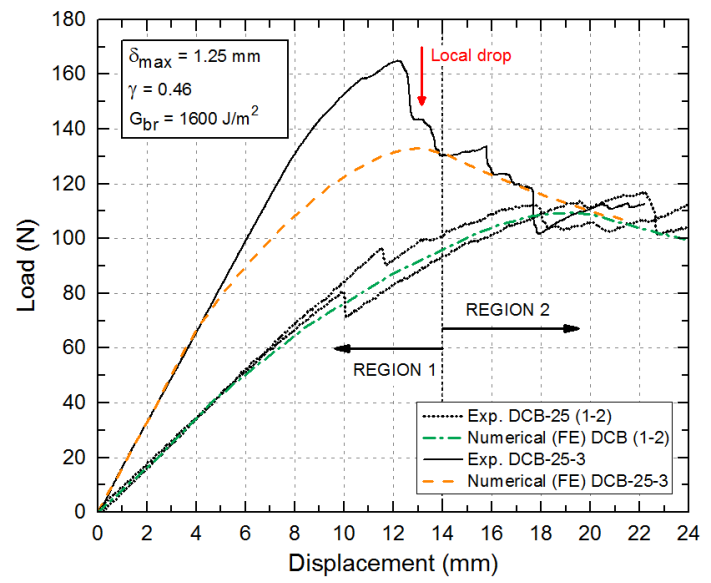

Fig. 19. Comparison of experimental and numerical curves of DCB-25 (1-2) and DCB-25-3 (cut from plate CFM.1) 


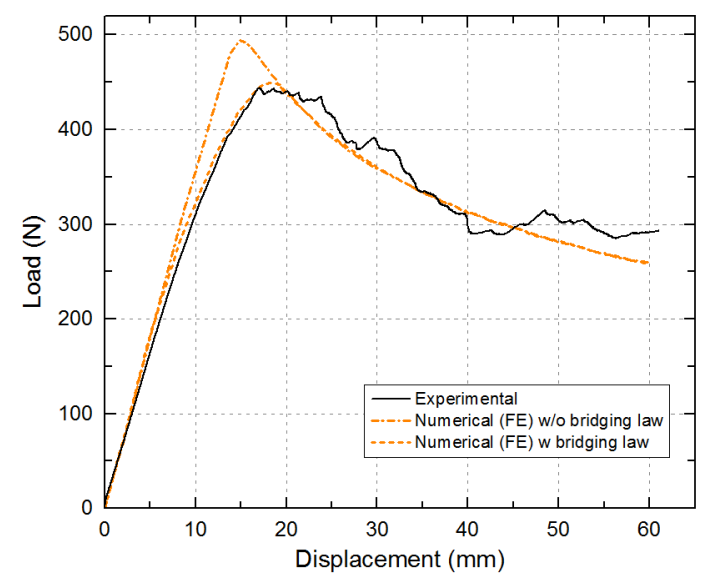

Fig. 20. Influence of shape of cohesive law in DCB-100-2: with and without bridging law.
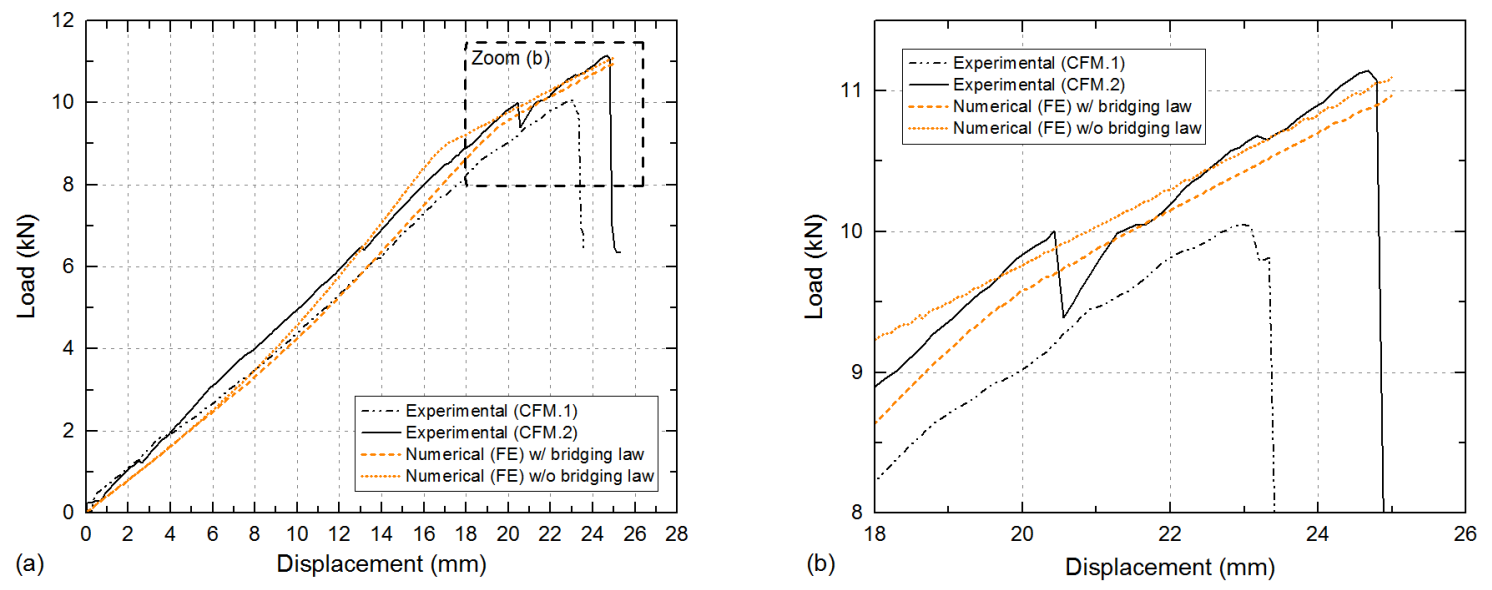

Fig. 21. (a) Influence of shape of cohesive law in plates: with and without bridging law; (b) zoom of region indicated in (a). 